\title{
Age related variations in the morphometric parameters of the mitral valve complex- A cadaveric based study from Kolkata
}

\author{
Rajasri Chunder ${ }^{1}$, Sayantani Majumdar ${ }^{2}$, Arijit Dey ${ }^{3}$ \\ ${ }^{1}$ Professor and Head, ${ }^{2}$ Assistant Professor, Department of Anatomy, Jagannath Gupta Institute of Medical Sciences \\ and Hospital, ${ }^{3}$ Senior Resident, Department of Forensic Medicine and Toxicology, AllMS, New Delhi
}

Background: Mitral valve diseases are quite common in Indian Population across the age groups and the latest trend in the valvular surgery for better outcome is "Respect rather than Resect". So, reconstructive surgeries being a preferred modality of treatment in Mitral Valvular Disorders, morphometric parameters of mitral valve are of immense importance. Aims and Objective: This study deals with the age wise variation of the morphometric parameters of the mitral valve. Material and Method: In this study, fifty formalin hardened cadaveric hearts were studied which were dissected and measurements of the morphometric parameters were recorded and analysed. Results: While analyzing the data on the weight of the heart, mean annular circumference (MAC), antero-posterior (APD) and transverse diameter (TD) of the mitral valve annulus, it was observed that all the parameters significantly increases with age. Conclusion: This data will be immensely helpful in planning the reconstructive surgeries of mitral valve age-wise.

Key words: Mitral valve; Mean annular circumference (MAC); Antero-posterior diameter (APD); Transverse diameter (TD); Reconstructive surgeries

\section{INTRODUCTION}

Diseases of the mitral valve (MV) are the second-most common clinically significant form of valvular defect in adults. In particular, MV regurgitation occurs with increasing frequency as part of degenerative changes in the aging process. The annual incidence of degenerative MV disease in industrialized nations is estimated at around $2 \%$ to $3 \%{ }^{1,2}$ In addition to degenerative changes, other causes of clinically significant MV regurgitation include cardiac ischemia, infective endocarditis and rheumatic disease more frequently in less developed countries. Mitral valve disease in the pediatric patient is quite variable and ranges from a routine cleft in the anterior leaflet of the mitral valve to complex mitral stenosis associated with Shone's complex or hypoplastic left heart syndrome (HLHS). Further complicating the management of these children are the associated concomitant cardiac lesions, which can dramatically affect clinical outcomes.
Mitral valve replacement (MVR) has been associated with significant morbidity ${ }^{3}$ in the pediatric population in the adult population also, mitral valve replacements especially in the developing countries are essentially not preferred because of their huge post operative lifelong cost of therapy. Thus considerable attention has been directed to mitral valve reconstruction in children over the last decade ${ }^{4,5}$ as well as the adults in the developing countries. ${ }^{6,7}$ As Mitral valve reconstructive surgeries are being increasingly preferred, know how on the comparative study of the different morphometric parameters of the mitral valve complex in the adult and pediatric population will help the surgeons to fix precise surgical guidelines for the age groups.

\section{AIMS AND OBJECTIVE}

A new concept of 'respect rather than resect' tissue has become popular in recent years. Valve repair in 
patients with degenerative MV disease is associated with an improved quality of life with less morbidity as well as better long-term survival as opposed to replacement ${ }^{8-11}$ Prosthesis-related morbidity, including higher re-operation rates, and the need for aggressive anticoagulation account for this difference both in adults and pediatric age group. Such increasingly frequent use of conservative surgical techniques have increased the interest in the anatomy of the heart. Detailed knowledge of the design of the normal mitral valve, responsible for its efficiency and longevity, as well as the knowledge of variations of its geometry in both adult and pediatric age group is important to obtain better results in conservative procedures, promoting return to anatomical and functional normality.

\section{MATERIALS AND METHODS}

The present study analyzed sixty healthy and fresh human hearts collected from the Calcutta Police Morgue from disease - free cadavers where the cause of death was accident. The study was done in three age groups: 0-20 years, 21-40 years and 41-60 years and above. In the first group ( $0-20$ yrs), 10 hearts were studied, the other two groups had 20 specimens in each group.

Weight of hearts was measured after taking out the specimens from the dead body. Mitral Valves were studied from the Atrial and Ventricular surfaces after opening the respective chambers with suitable incisions and washing the interior with tap water. Position of the mitral valve cusps the commissures, scallops, clefts, notches, attachments of the chordae tendinae and positions of the papillary muscles were observed. The following two morphometric parameters of the mitral valve complex were measured in fresh state:

Total circumference of the mitral valve annulus Figure 1.

Maximum transverse Figure 2 and AP Figure 3 diameters of the mitral annulus and their ratio.

\section{RESULTS}

It was observed that heart weight increased with progress of age. The mean weight of the heart in the $0-20$ years, 21 40 years and $41-60$ years was found to be 176.5 grams, 237.8 grams and 280.55 grams respectively as shown in Table 1.

The mean annular circumference (MAC) of the mitral orifice in the 0-20 years, 21-40 years and 41-60 years was found to be 7.2, 8.4 and 9.93 respectively as reflected in Table 2 .

The maximum mean Transverse and Antero-Posterior diameter (APD) of mitral orifice at the annulus in the 0-20 years, 21-40 years and 41-60 years was found to be 1.7, 2.3 and 2.9 for the antero-posterior diameter and 2.4,2.9 and 4 for the transverse diameter(TD) as seen in Table 3 and Table 4.

\section{DISCUSSION}

Gardner et al. (1971) ${ }^{12}$ showed that the mean heart weight in males is around $328 \mathrm{gm}$, varying from $256 \mathrm{gm}$ to $390 \mathrm{gm}$



Figure 1: A specimen of the Human heart showing the Mitral valve annulus (marked in red) surrounding the mitral orifice (MO). The annulus gives attachment to the two leaflets- anterior $(\mathrm{AL})$ and posterior $(\mathrm{PL})$. The leaflets give attachments to the chordate tendinae(C) on the ventricular surface. The anterior aspect of the heart marked as ANT

\begin{tabular}{|c|c|c|c|c|c|}
\hline Age Group & Minimum & Maximum & Range & Mean & Standard deviation \\
\hline $1-20$ & 145.0 & 200.0 & 55.0 & 176.500 & 18.7157 \\
\hline $21-40$ & 198.0 & 267.0 & 69.0 & 237.800 & 19.9779 \\
\hline $41-60$ & 250.0 & 300.0 & 50.0 & 280.550 & 15.3365 \\
\hline
\end{tabular}

Table 2: Annular circumference of mitral valve annulus

\begin{tabular}{|c|c|c|c|c|c|}
\hline Age Group & Minimum & Maximum & Range & Mean & Standard deviation \\
\hline $1-20$ & 6.8 & 7.9 & 1.1 & 7.230 & 0.3268 \\
\hline $21-40$ & 7.5 & 9.2 & 1.7 & 8.405 & 0.3993 \\
\hline $41-60$ & 9.3 & 10.5 & 1.2 & 9.935 & 0.3438 \\
\hline
\end{tabular}


Table 3: Transverse diameter of mitral valve annulus

\begin{tabular}{lccccc} 
Age Group & Minimum & Maximum & Range & Mean & Standard deviation \\
\hline $1-20$ & 2.1 & 2.9 & 0.8 & 2.470 & 0.2497 \\
$21-40$ & 2.7 & 3.2 & 0.5 & 2.985 & 0.1387 \\
$41-60$ & 3.6 & 4.5 & 0.9 & 4.095 & 0.2089 \\
\hline
\end{tabular}

Table 4. Antero-posterior diameter of mitral valve annulus

\begin{tabular}{lcccc}
\hline Age Group & Minimum & Maximum & Range & Mean \\
\hline $1-20$ & 1.5 & 2.2 & 0.7 & 1.700 \\
$21-40$ & 2.0 & 2.6 & 0.6 & 2.340 \\
$41-60$ & 2.7 & 3.1 & 0.4 & 0.2309 \\
\hline
\end{tabular}

and in females around $244 \mathrm{gm}$, ranging from $198 \mathrm{gm}$ to 270 gm. Linzbach $(1960)^{13}$ however stated that the weight of the human hearts without pathological alterations can reach upto $500 \mathrm{gm}$. The present study showed that the weight of the heart ranged from $145 \mathrm{gm}$ to $200 \mathrm{gm}$ in the age range between 1-20 years, with a mean of $176.5 \mathrm{gms}, 198 \mathrm{gms}$ to $267 \mathrm{gms}$ in the age range between 21 to 40 years with a mean of 237.800 gms. and 250 to $300 \mathrm{gms}$ in the age range of $41-60$ with a mean of 280.550 gms.

Perloff and Roberts (1972) ${ }^{14}$ emphasized that the mitral valve is best considered as a complex of components parts, all of which needed to function properly so as to ensure valvar competence. The parts of this complex are as follows:

- Left atrio-ventricular orifice

- The mitral annulus (together with the insertion of atrial myocardium around the vestibule of the valve)

- Leaflets of the mitral valve

- The chordae tendinae

- The papillary muscles \& the supporting ventricular myocardium

A.K. Datta $(1984)^{15}$ measured the circumference of mitral annulus in various age groups and found the circumference of mitral annulus between 1 - 20 years of age is $6.9-9.6 \mathrm{~cm}, 20-40$ years it is $9.9-10.9 \mathrm{~cm}$ and above 40 years $11.3-12.1 \mathrm{~cm}$ and their findings proposed that the mitral circumference increases with advancing age. Kitzman DW, Edwards WD $(1990)^{15}$ found that with advancing age there are significant increases in heart weight, ventricular septal and probably left ventricular free wall thickness and valve circumferences. ${ }^{15}$ In the present study, the mitral annulus circumference in various age groups was measured and the study observed that there is increase in the circumference with the advancing age. Scholz et al. $(1988)^{16}$ studied age changes within the normal human heart from formalin-fixed cadavers where the age was between birth and 19 years. The circumferences of all four heart valves were measured The results found that there was a correlation between valve circumferences and age in



Figure 2: A specimen of the Human heart showing the Mitral valve annulus (marked in red) surrounding the mitral orifice (MO). The annulus gives attachment to the two leaflets- anterior (AL) and posterior $(\mathrm{PL})$. The transverse diameter (marked in blue) of the annulus is measured by slide callipers (SC)

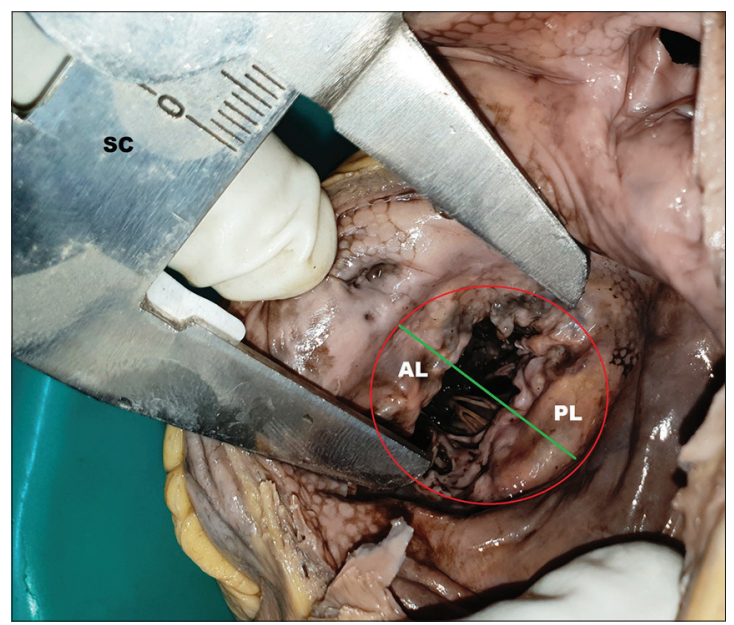

Figure 3: A specimen of the Human heart showing the Mitral valve annulus (marked in red) surrounding the mitral orifice (MO). The annulus gives attachment to the two leaflets- anterior (AL) and posterior $(\mathrm{PL})$. The anterior-posterior diameter of the annulus marked in green. The measurements are done by slide callipers (SC)

all four heart valves in both sexes. The circumference of the valves were increased with increasing age, ${ }^{16}$ the results 
being similar to the present study. In the Mitral valve, the closing edge (rough zone) of each leaflet is thicker than the rest of the valve and this is more pronounced in the anterior leaflet than in the posterior. Mitral valve leaflets become less translucent with age and adipocytes and lipid deposits accumulate within the leaflet tissue, especially on the ventricular surface and in the zona spongiosa. Nodular thickening often can be seen along the lines of closure on both leaflets, likely due to repeated trauma caused by valve closure. With increasing age, collagen deposition, degeneration, lipid accumulation and dystrophic calcification of the annulus is seen. Lambl's ${ }^{17}$ excrescences are increasingly found with advancing age and were reported in almost all subjects over 60 years of age. They are found on the atrial surface of the leaflets, usually along the line of closure. ${ }^{17}$ In the present study, It is evident that the mean surface area and the length of both anterior and posterior leaflets increases with age.

\section{CONCLUSION}

It is seen in the study that all the morphometric parameters of the mitral valve increases with age and this has got significance in the planning of mitral valve reconstructive surgeries in mitral valve disorders.

\section{REFERENCES}

1. Enriquez-SM, Akins $\mathrm{CW}$ and Vahanian A. Mitral regurgitation. Lancet 2009; 18;373(9672):1382-1394.

2 Anders S, Said S, Schulz F and Püschel K. Mitral valve prolapse syndrome as cause of sudden death in young adults. Forensic Sci Int 2007; 171(2-3):127-130.

3. Caldarone CA, Raghuveer G, Hills CB, Atkins DL, Burns TL, Behrendt DM, et al. Long-term survival after mitral valve replacement in children aged $<5$ years: a multi-institutional study. Circulation 2001; 104(12 Suppl 1):1143-1147.

4. Stellin G, Padalino MA, Vida VL, Boccuzzo G, Orrù E,Biffanti R, et al. Surgical repair of congenital mitral valve malformations in infancy and childhood: a single-center 36-year experience. J Thorac Cardiovasc Surg 2010; 140(6):1238-1244.

5. Wood AE, Healy DG, Nolke L, Duff D, Oslizlok P and Walsh K. Mitral valve reconstruction in a pediatric population: late clinical results and predictors of long-term outcome. J Thorac Cardiovasc Surg 2005; 130(1):66-73.

6. Falk V, Seeburger J, Czesla M, Borger MA, Willige J, Kuntze T, et al. How does the use of polytetrafluoroethylene neochordae for posterior mitral valve prolapse (loop technique) compare with leaflet resection? A prospective randomized trial. J Thorac Cardiovasc Surg 2008; 136(5):1205-1206.

7. Seeburger J, Kuntze T and Mohr FW. Gore-tex chordoplasty in degenerative mitral valve repair. Semin Thorac Cardiovasc Surg 2007;19(2):111-115.

8. David TE, Ivanov J, Armstrong $S$ and Rakowski $H$. Late outcomes of mitral valve repair for floppy valves: Implications for asymptomatic patients. J Thorac Cardiovasc Surg 2003; 125(5):1143-1152.

9. Enriquez-Sarano M, Schaff HV, Orszulak TA, Tajik AJ, Bailey KR and Frye RL. Valve repair improves the outcome of surgery for mitral regurgitation. A multivariate analysis. Circulation 1995; 15: 91(4):1022-1028.

10. Gillinov AM, Blackstone EH, Nowicki ER, Slisatkorn W, AlDossari G, Johnston DR, et al. Valve repair versus valve replacement for degenerative mitral valve disease. J Thorac Cardiovasc Surg 2008;135(4):885-893.

11. Suri RM, Schaff HV, Dearani JA, Sundt TM, Daly RC, Mullany CJ, et al. Survival advantage and improved durability of mitral repair for leaflet prolapse subsets in the current era. Ann Thorac Surg 2006; 82(3):819-826.

12. Gardner, Ernest; Gray, Donald J; O'Rahilly, Ronan; Benevento, Rogerio. Anatomia: Estudo regional do corpo humano/Anatomia: Estudo regional do corpo humano. Rio de Janeiro; Guanabara Koogan; 1978. 815.

13. Linzbach AJ. Heart failure from the point of view of quantitative anatomy. Am J Cardiol 1960; 5:370-382.

14. Perloff $\mathrm{J}$ and Roberts $\mathrm{W}$. The mitral apparatus, functional anatomy of mitral regurgitation. Circulation 1972;46(2):227-239.

15. Kavimani M, Morphology and Morphometric analysis of the human mitral valve complex. (Unpublished work).

16. Gumpangseth T, Mahakkanukrauh $P$ and Das S. Gross agerelated changes and diseases in human heart valves. Anat Cell Biol 2019; 52(1): 25-33.

17. Butany J, Ahluwalia $\mathrm{M}$ and Feindel C. Age-related morphological changes in cardiac valves. Geriatrics and Aging 2003; 6(9): 49-54.

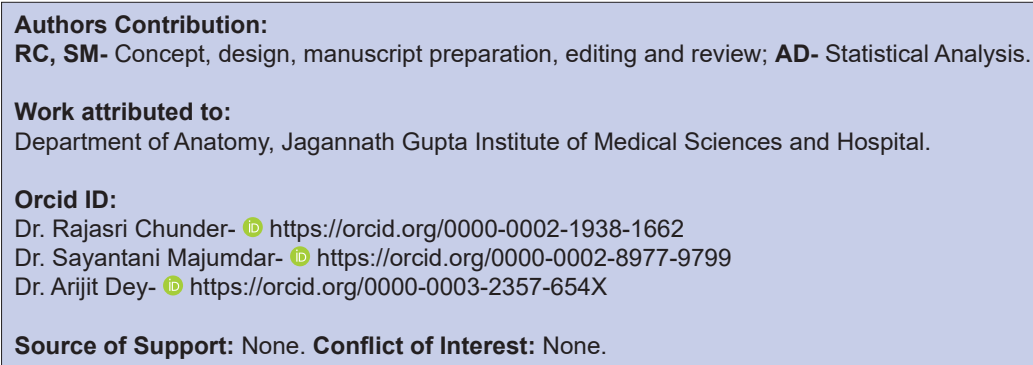

